\title{
A Strange Kind of Marriage: The Challenging Journey of Entertainment-Education Collaboration
}

\author{
Martine Bouman
}

In the early days of entertainment-education (EE), the focus was on theatre, music, film, radio, and television. Nowadays the media landscape offers a rich variety of linear, as well as online and digital media, culminating in transmedia formats. What does this mean for EE collaboration partnerships? Which facilitating or hindering factors play a role in the collaboration between health communication and other professionals when making an EE media program? What are theoretical and creative elements for the design of stories for social change? What new skills do entertainment-education professionals need in a digital era? These are challenging questions for EE researchers and practitioners. In this chapter, the different stages of my challenging journey in EE collaboration will be illustrated.

\footnotetext{
M. Bouman ( $\square)$

Center for Media \& Health, Gouda, The Netherlands

e-mail: bouman@media-gezondheid.nl

(C) The Author(s) 2021 


\section{INTRODUCTION}

I remember my own first steps in the field of entertainment-education. In the mid-1980s, I watched the popular prime time television sitcom Zeg eens $A$, which was broadcast in the Netherlands. ${ }^{1}$ The series took place in a general practitioner's office and portrayed the daily lives of a doctor and her patients. I had just started to work as a health communication professional at the Netherlands Heart Foundation (NHF). Health communication was a fairly new discipline, and often social scientists like me were appointed to develop new health promotion policies. Soon after my start at the NHF, I discovered that epidemiological studies in the Netherlands (and in other countries) showed that people with a lower socioeconomic status (meaning those with lower income, education, and job status) lived an average of seven years less and experienced health problems twelve years earlier than higher socioeconomic status groups (Mackenbach, 1994). I found this data shocking. These enormous health inequalities made me realize that we often do not effectively reach the people who need our health information most, not because they are difficult to reach, but because our traditional communication methods are not attuned to their culture and preferences. This was a wake-up call for me. I understood that it was no longer sufficient to rely solely on a cognitive approach and the rationality of the health message; other, more emotionally appealing and popular communication methods also needed to be brought into play. I started watching $Z e g$ eens $A$ with new eyes. I realized that embedding storylines in a popular drama series could be an excellent way to introduce and discuss health issues. I became intrigued by the power of storytelling for health communication, and at the NHF I had the opportunity to experiment with the entertainment-education communication strategy on television. Many years later, in 1999, I founded the independent research institute Center for Media \& Health $(\mathrm{CMH})$ to further develop the EE field in the Netherlands, which resulted in several award-winning projects. Since 2015 I combine my work at $\mathrm{CMH}$ with teaching at the Erasmus University in Rotterdam as holder of the special chair Entertainment Media and Social Change (Bouman, 2016). Over my thirty five years of working in EE, I have learned many lessons, and I am happy to share some of them in this chapter.

\footnotetext{
${ }^{1}$ Zeg eens $A$ was broadcasted by the VARA from 1981 to 1993 and was watched by an average of four million viewers (out of a total population of 15 million) until 1991.
} 


\section{EnTERTAinMENT-Education COllaboration}

While working for the NHF on a nationally broadcast heart health game show, Joop van den Ende, head of the production company, took me aside after a discussion with the director of the show, and told me, "Please Martine, you have to remember, scriptwriters are very sensitive people." It took me several years to find out what he really meant. When I studied the EE collaboration process in more depth, I found that media professionals eschew scholarly oversight of their work when displaying their artistry (like peacocks), while the content-driven health professionals are steeped in scientific and slow bureaucratic procedures (like turtles).

As described in my book, The Turtle and the Peacock, "Entertainmenteducation strategy is the process of purposively designing and implementing a mediating communication form with the potential of entertaining and educating people, in order to enhance and facilitate different stages of prosocial (behavior) change" (Bouman, 1999, p. 25). The word 'process' in this definition is very important. It reflects the time, energy, and 'process way of thinking' that is needed when the EE communication strategy is applied. An EE collaboration is a strange kind of marriage. I have learned that it's a matter of careful balancing between content and form, and between different stakeholders and collaboration partners. Several facilitating and hindering factors play a role in the collaboration, such as differences in work culture and professional standards, as well as personal traits and preferences. I remember a conversation between a health communication professional and a scriptwriter. The health communicator had a lot of ideas, but also wanted to distinguish himself from the 'lesser' world of soap series. So he started his meeting with the scriptwriter by announcing, "I am not a fan of soap series, and I never watch this genre myself" (Bouman, 2016, p. 23). His slight but unmistakable disdain immediately set the tone. When there is no genuine interest and respect for each other's professional domain, the EE collaboration is doomed to fail. At that time, collaborating with scriptwriters of popular television programs was still a challenging and problematic issue, due to the fact that health organizations had great initial reservations about using a popular medium for their health communication. Tabloids, soap operas, or drama series were considered to be too profane for the serious and important health messages of the highly esteemed health organizations. Apart from their unfamiliarity with popular culture, health organizations feared losing their respectable image and, as an ultimate consequence, their funding. 
Although understandable, this shows an explicit tension between the goals of health communication and the goals of public relations and fundraising.

\section{Villa Borghese}

The NHF, however, was daring and innovative enough, and despite its unfamiliarity with popular media, it gave the green light for the design and implementation of a new EE drama series to stimulate a healthy lifestyle for the prevention of cardiovascular diseases. In 1992, this resulted in an EE co-production ${ }^{2}$; the NHF collaborated with a producer and broadcasting company, for the creation of a new prime time drama series called Villa Borghese (VB). Villa Borghese was a fictitious Dutch health farm that included a restaurant, swimming pool, and fitness center. In this setting, heart patients and regular customers were offered advice, training, and therapy, to better understand the importance of regular exercises, a balanced diet, non-smoking, and dealing sensibly with stress. The aim of the series was to move social norms in the direction of a healthy lifestyle. The main characters of the series, primarily staff and customers at the health farm, had to be on the 'winning side' and attractive to identify with (Fig. 5.1).

By designing a new series, it was possible to apply the theoretical framework and guidelines of EE soap series (such as using positive, transitional and negative role models) as formulated by Miguel Sabido (Nariman, 1993). The co-production arrangement in Villa Borghese involved a joint decision-making process in all stages of the production, from reading the first scripts to directing the last cuts. The main challenge in this collaboration process was how to frame and integrate the issue of cardiovascular diseases into a compelling story and how to create a good balance between entertainment and education. Difficult as it was, this was not the only challenge I met. As a newcomer in the EE field, I had to make sense of particular situations (Louis, 1980; Weick, 1995). I was not yet equipped to immediately understand what the creative professionals were doing. I had to understand the puzzles and uncertainties in the creative process of making an EE drama series and find ways to cope with different professional backgrounds and attitudes.

\footnotetext{
${ }^{2}$ In an EE co-production partners collectively design, produce, and broadcast/launch a new entertainment program for social change purposes (Bouman, 1999).
} 


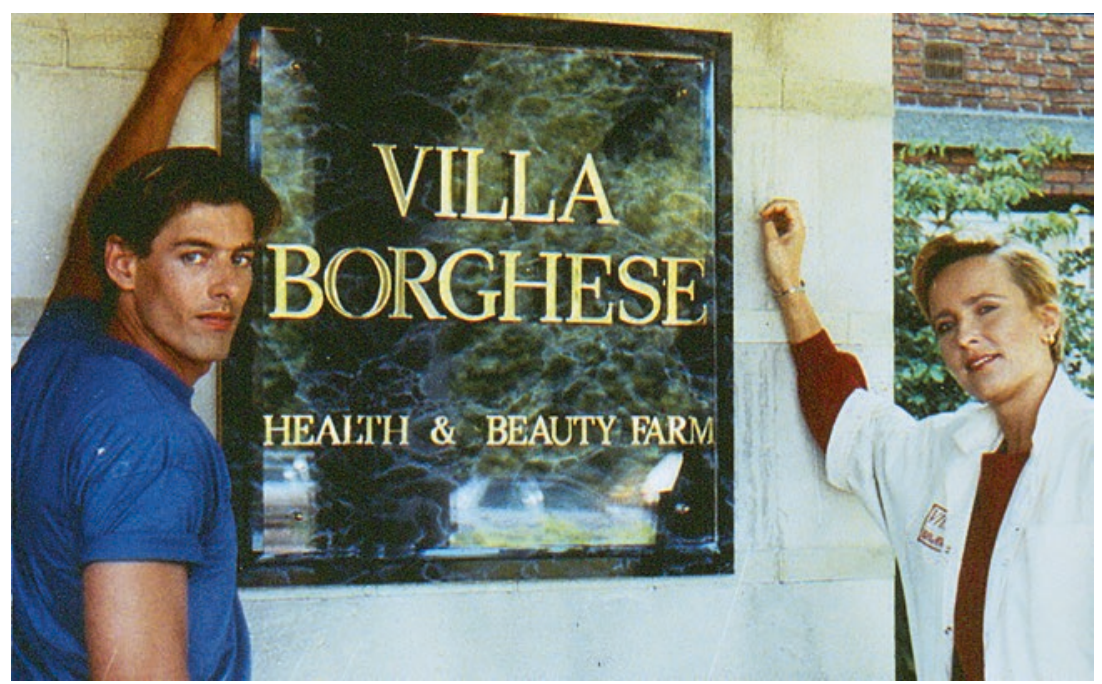

Fig. 5.1 Villa Borghese: Health \& Beauty Farm. (Source: CMH with permission of AVRO broadcasting company)

\section{Different Ways of Thinking}

Later, during my own research into EE collaboration processes, I learned that the creative process to design an entertaining media format calls for a different way of thinking than that of the scientifically trained health professional (Bouman, 1999, p. 189). As a health communication professional, I was trained in a verbal, analytic, and logical way of thinking where objective information, truth, balancing of values, and standardized protocols are most important. Creative media professionals tend to have a more nonverbal, synthetic, and intuitive way of thinking, in which creativity, originality, spontaneity, and authorship are important. A health communication professional that I once interviewed illustrated this with the remark, "Brainstorming for television professionals often means creating all kinds of ideas and acting out every wild fantasy, although there is a limited budget, that allows for only so much of the expressed ideas. Then we had to sober them up and calculate the possibilities. Often enough it appeared that some of the ideas were not at all feasible, for example, that the stars they had in mind were never available" (Bouman, 1999, p. 188). This interviewee found that television professionals indulged in fantasies, and 
they let their imagination run away with them. With my scientific background, I also often felt the urge to pull the creative team back to earth. We all enter the process with our own professional standards and frames of references. I recognized on many occasions that I had to learn to build bridges between the two different modes of thinking, and in order to do that, I had to explore the creative realm of the media professional. Villa Borghese made me fully realize the importance of familiarizing myself with the field of the media professional. The experience contributed to the 'The Turtle and the Peacock' effect that I described in my book.

For Villa Borghese, however, this insight came too late. Despite good intentions, the health messages that were incorporated in the drama proved to be too explicit and overly didactic. The storyline lacked enough suspense and developed too slowly. Apart from lack of experience in designing EE drama, this was due to the fact that the educational content was brought into play too quickly. The series suffered from imbalances between entertainment and education. This outcome led to an important insight for the developing EE strategy: when writing drama for educational purposes, the entertainment comes first. With Villa Borghese, we were too keen to bring our message. That didn't help. We gained only half of the viewer ratings that we hoped for; the time to gain rapport with our audience and create a fan base proved to be too short (Bouman \& Wieberdink, 1993; ResCon, 1992). Due to the low ratings, there was no second season of the series.

\section{Medisch Centrum West (MCW)}

Our interest in the EE strategy, however, hadn't wavered. On the contrary, it was a 'failing forward,' making it worthwhile to explore the power of storytelling for social change on entertainment media. To avoid the risk of failing again in winning an audience for a new series, the NHF chose to incorporate heart health storylines into an already existing series. This resulted in a formal arrangement (so called in-script participation) with the producer of the very popular prime time hospital series Medisch Centrum West (MCW).

MCW was based on realistic medical themes and was written around romances and intrigues between doctors and nurses (similar to the series Greys Anatomy in the USA). Many families sat together watching this series. The observation that audiences become 'medical voyeurs' makes such series very appealing and attractive (Karpf, 1988; Turow, 1989). 
As a health communication professional and delegate producer of the NHF, I briefed the scriptwriting team of MCW and checked the content of the cardiovascular health message for its medical soundness and educational value. In this way, several cardiovascular health themes were incorporated in different episodes. That wasn't always easy. The collaboration showed what I had noticed before: the professional way of thinking of the health professional and that of the scriptwriter aren't a natural match. I remember a discussion with the scriptwriter of MCW about a specific storyline around nutrition and heart health risk. From the start, he wasn't very happy about the whole idea of incorporating a heart health message in his storyline. At some point, in a heated discussion about how to bring the concept of a healthy diet after a heart attack, he told me rather desperately: "Hey Martine, I can't dramatize a meatball, you know!" But after a few drinks our conversation mellowed, he accepted the challenge, and later on even started to enjoy it. This particular collaboration also taught me that certain terms and words, such as education and target group, have a negative connotation for the scriptwriter, illustrated by his remark, "I'm not an educator. I am a storyteller.”

Our participation in MCW gave us the opportunity to do some research. For the evaluation, we developed a novel research design. Because of practical problems in relation to baseline studies (it is a nationally broadcast series and you can't exclude people from watching it), a post-test only design with non-equivalent groups was used. This design is often used in media effect research, despite its methodological limitations. Without a baseline test, it is more difficult to measure possible changes in knowledge, attitude, or behavior. To compensate for this, we selected and interviewed three subsamples: (1) regular MCW viewers who saw the specific cardiovascular health episode, $(2)$ regular MCW viewers who normally watch the series but missed the specific cardiovascular health episode, and (3) nonMCW viewers. Comparison of the first two groups is of special interest here, and not often found in other media research. The evaluation showed that respondents who had watched this specific storyline in MCW scored significantly higher on knowledge items than regular viewers who had missed that specific episode (Bouman, 1999; Bouman, Maas, \& Kok, 1998). Although the viewers were well aware that the specific episodes in MCW included health messages, they didn't find that intrusive for their enjoyment. And, most importantly, more viewers from lower socioeconomic groups had watched MCW than higher socioeconomic groups, suggesting we reached our intended audience. 


\section{Fields of Practice}

I learned from my first EE experiments with Villa Borghese and Medisch Centrum West that the use of the EE strategy in health communication can only be successful if all involved parties work collaboratively. As described in The Turtle and the Peacock (Bouman, 1999), designing and implementing EE projects means sitting together to negotiate, brainstorming, creating ideas, and putting them into practice. This is an 'intercultural' EE collaboration process where all professionals involved have to make sense of their collaboration. Bridging different cultures, work rhythms, and professional dilemmas play an important role. Often notions of power and control convert the arrangement into a negotiated agreement. The French sociologist Pierre Bourdieu (1993) offers an interesting perspective on the struggles between different fields of practice; in this case the health communication field and entertainment media field. For example, a health organization may lose its symbolic capital (goodwill) among its donors and stakeholders by collaborating in a popular media format, while media professionals may gain prestige by collaborating with a respected health organization. When different professional domains want to collaborate, they have to have a feel for the game and know the mode of life (babitus) of that specific field. That is an investment that needs to come from both sides. Health communication professionals indicated that they always felt a natural tension during the collaboration, due to the different aims, goals, professional standards, and perspectives that had to be reconciled. They were aware that, in general, television professionals did not like outside influence on the program. Television professionals said that they were willing to listen to health communication professionals, so long as they could benefit from their expertise. They liked to collaborate with competent professionals. As one television professional said, "The more competent and intelligent the player, the more interesting the game" (Bouman, 1999, p. 170). They found it difficult to collaborate with health communication professionals who believed that they were competent players, but who in their eyes were not.

\section{EE Media Mapping Model}

Although the result of a creative process cannot be predicted in detail, because both EE partners influence the final product, there are certain logical steps in every EE collaboration process. Based on my previous experience in Villa Borghese and Medisch Centrum West, I developed a 


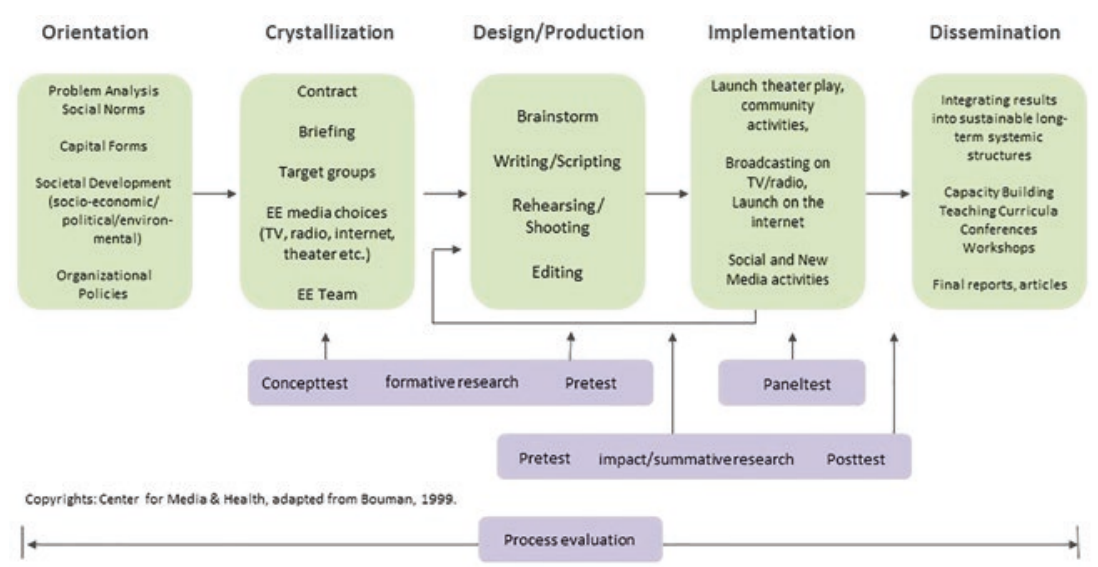

Fig. 5.2 Entertainment-Education Media Mapping Model

mapping model for the design and production of an EE program (see Fig. 5.2). This EE Media Mapping Model makes it possible for collaboration partners to follow the design stages of an EE project in a transparent way. In every stage, all collaboration partners are engaged in a 'give and take' kind of interaction as the members of the EE team clearly do not collaborate in a vacuum. They are tied to several other reference groups and important others (colleagues, board of directors within the organization, other professionals in the sector, the press). By nature, such a framework is rather static and linear. In practice the stages sometimes overlap and are more dynamic. For analytical reasons however, and for a better understanding of the collaboration process, the different stages are defined and distinguished. In the first stages (orientation, crystallization) the health organization is more in the lead. As soon as the production stage starts, the media organization takes over. In the dissemination stage, the health organization comes to the fore again.

\section{EE in the New Media Landscape}

Medisch Centrum West and Villa Borghese were both based on linear storylines, meant for broadcasting on television. Since the introduction of the Internet, the media landscape offers a much richer variety of digital media formats (blogs, vlogs, web series), and transmedia formats with 360 degree storytelling. Transmedia storytelling is a promising new EE format (Wang 
\& Singhal, 2016, 2018) and orchestrates elements of a story across multiple platforms, thereby providing entry points through various channels (Jenkins, 2006). Characters that play a role in the narrative can post blogs or video diaries about their own experiences and can include links to public health services and reliable information sources. The storyline can also transcend the media environment and unfold at real-life events (e.g., organizing a 'meet and greet' of the main characters of a series in a real-life restaurant or nightclub).

There has been a shift from the age of the broadcasting schedule, where audiences adapt to the timetables of television broadcasters to see their favorite series and shows, such as Medisch Centrum West and Villa Borghese, to the age of the stream, where audiences choose from a continuous stream of media content whenever they choose (Lutkenhaus, Jansz, \& Bouman, 2019). What does this mean for EE collaboration partnerships?

\section{SOUND}

My first collaboration experience in designing an EE format in the new media landscape was in 2008. In order to persuade youth to protect their hearing by wearing earplugs while clubbing, we designed and launched ${ }^{3}$ the campaign Sound Effects. The average sound level in discotheques ranges from 104 to 112 decibels, a range that exceeds all international statutory safety standards for occupational settings. Exposure to dangerously loud music at concerts, discotheques, and dance events has caused a lot of hearing loss among Netherland's youth. Such a loss approaches the qualification for a social handicap, as it prevents those who suffer from following conversations in large groups.

Our challenge was to combine theory, research, and practice in an integral approach. Sound Effects involved online and offline media, peer education, and collaborative partnerships with discotheques, the music sector, and media partners. Our main media partner was Endemol Productions, an international Dutch production company. In designing the Sound Effects campaign, we used principles from the field of health communication, entertainment-education, social psychology, celebrity endorsement, and social marketing.

In order to effectively design the Sound Effects campaign, we executed online chat session interviews as part of the extensive formative research

\footnotetext{
${ }^{3}$ In collaboration with the Municipal Health Service of Amsterdam.
} 
among youth aged 16-30 (Bouman \& Jurg, 2006; Rijs, Meeuse, Jurg, \& Bouman, 2007). These chat sessions with members of the target group were of great value, because they delivered several quotes that we could literally use in the drama and other parts of the campaign.

To tailor the campaign, we looked closely to our research data. They showed that some youth were not interested or engaged in the issue of hearing loss, while others were already contemplating taking preventive measures. ${ }^{4}$ This meant that we needed to diversify our communication strategy. We decided to experiment with the design of a 'central route' and a 'peripheral route' for the persuasion process, as described in the Elaboration Likelihood Model (Petty \& Cacioppo, 1986; Slater \& Rouner, 2002). Although the two routes of persuasion were closely linked, we gave them a totally different look and feel, in order to create a different approach for youth who were not yet interested in hearing loss prevention and youth who were already motivated to take preventive measures while clubbing. The overall Sound Effects campaign consisted, therefore, of two separate campaign tracks (see Fig. 5.3): the SOUND track (peripheral route) and the GoOut PlugIn track (central route). We designed an online mini soap SOUND and website for the peripheral route, using an affective approach with heuristic cues to attract the attention of youngsters who were not yet interested. At the end of each episode of the Sound series, youth could link to the GoOut PlugIn track for more information. GoOut PlugIn was based on a cognitive approach where youth could find factual information on hearing loss (website flyers, posters, decibel indicators, and peer education at music venues). For each track, unique materials were designed, and communication to the press was carefully channeled in separate press releases.

A key element of this strategic communication campaign was the nineepisode web series ( 2.5 minutes per episode) SOUND, about 'love, ambition and decibels,' that we designed in collaboration with the Endemol media professionals. The script was based on the ideas, wishes, misconceptions, and experiences of the target group. Before writing the first synopsis of the SOUND series, I shared a briefing document with the scriptwriters of Endemol Productions, containing a description of the aims, target group, behavior change goals, and value grid for the series. This briefing

${ }^{4}$ (1) to wear earplugs with filters, (2) maintain a distance of at least two meters from loudspeakers, and (3) reduce the duration of exposure by taking regular 'ear breaks' in chillout rooms. 


\section{Sound Effects}

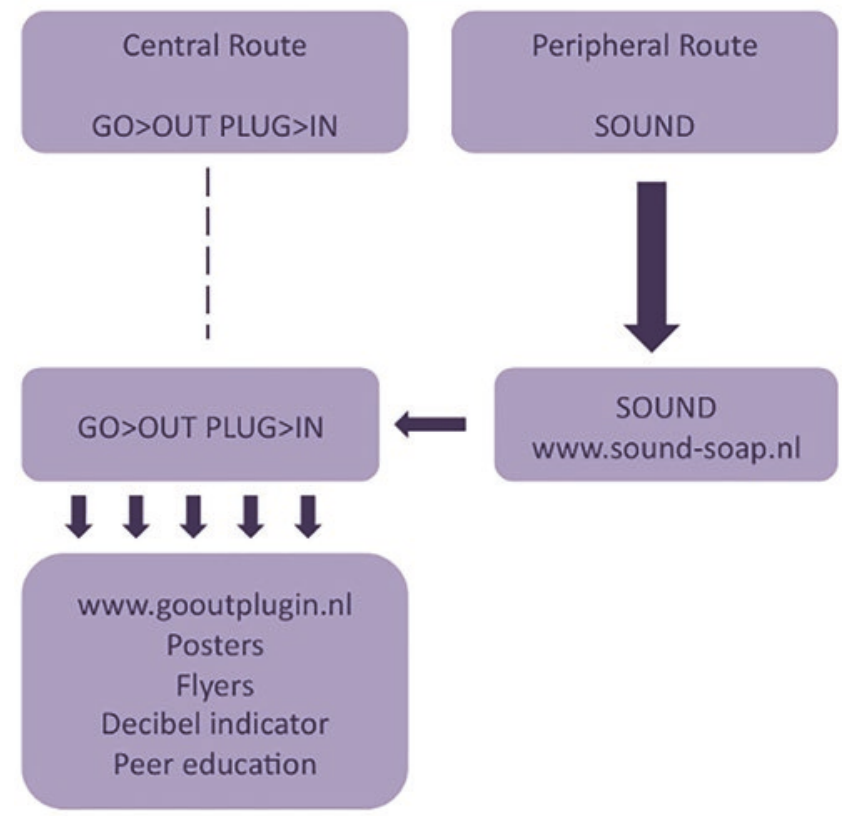

Source: Center for Media \& Health 2009

Fig. 5.3 Central and peripheral routes of the Sound Effects campaign

document also addressed some theoretical elements of the EE strategy, such as the use of Sabido's positive, transitional, and negative role model in the series (Nariman, 1993) (Fig. 5.4).

SOUND was the first EE online drama series in the Netherlands. What did we learn from this project in the new media landscape? It was a challenging process for all of us for many reasons. The production company Endemol had no previous experience writing and producing an online web series. They were very good writing daily soap series with 25 -minute episodes. The SOUND series, however, consisted of much shorter episodes. This meant they had to create very short spans, with cliff-hangers after every 2-3 minutes, instead of 25 minutes. Still, they used the same 
Fig. 5.4 SOUND

(Source: CMH: Casper

Cammeraat)

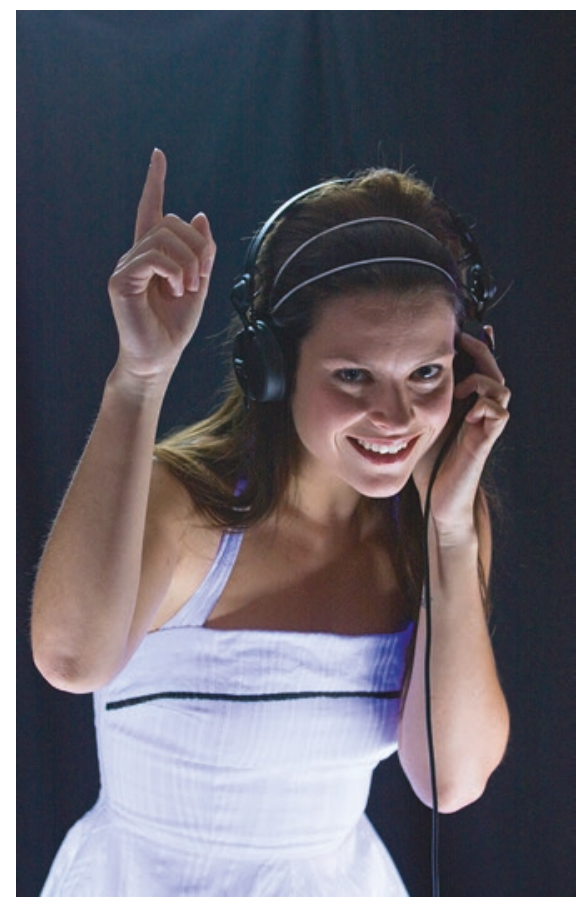

high-quality level for the production of SOUND as for their wide screen drama series. It was only after the series launch that they realized that youth watched SOUND on small computer screens via YouTube. In their opinion, this did not do justice to the high quality of their professional sound and image editing. For the campaign, however, the high quality was a big positive.

Our original idea was to upload a new episode of SOUND every week to create a tension arc during the whole nine-week campaign period. However, during the pre-test sessions, youth said they preferred to wait until all nine episodes were available online. They wanted to postpone watching in order to have immediate gratification. We changed our plans, and instead of launching one new episode weekly for nine weeks, we decided to upload three new episodes for three weeks in a row. It was interesting to see that we still used a linear way of thinking, as we were used to. 
A challenging part of going digital was creating an audience for the series. How could we inform youth that there was a new series online? In 2008, social media were still in their infancy. Twitter didn't exist, and Hyves (a popular Dutch Social Network) and Facebook were not yet widely used. CMH created both online and offline press releases and held a press meeting with Endemol Productions. To seed the new series, we posted a trailer on YouTube and various online social communities. This trailer raised the attention of the tabloid press, because the main characters of SOUND were popular actors in other well-known Dutch series. Journalists wanted to know whether the actors had quit the other series to start appearing in this new, mysterious SOUND series. When CMH and Endemol Productions held a press conference, my biggest challenge was to answer the questions of the press as honestly as possible, without disclosing the educational part of the series and putting too much emphasis on the hearing loss issue. It was important that youngsters would watch the series for its entertainment value. If they knew beforehand that the series also had an educational component, they might lose their spontaneous desire to watch. Forewarning is still an intrinsic dilemma of the entertainment-education strategy (Bouman, 1999, 2002).

With the Sound Effects campaign, we learned that an internet drama series needs a different type of publicity and launch than a television drama series. This requires a great deal of social media communication, ideally with viral content. We had underestimated the necessary budget for this type of social media campaigning. In the production of SOUND, most of the budget was spent on the high production quality of the drama; only a small budget was allocated for social media publicity (banners, trailers, chat sessions on web communities, etc.).

\section{SndBites}

The experiences and lessons learned in the Sound Effects campaign created a solid foundation for the exploration of another new EE format. Based on the experience of $S O U N D,{ }^{5} \mathrm{CMH}$ developed and launched a new interactive EE web series in 2011 called SndBites (SoundBites), targeted at lowereducated youth aged 15-18 (Bouman \& Hollemans, 2012),. The setting of SndBites was a nightclub, and the storyline dealt with several health issues (moderate alcohol consumption, hearing loss prevention, and safe

\footnotetext{
${ }^{5}$ In collaboration with Soa Aids Netherlands and the Trimbos Institute.
} 
sex). SndBites emphasized interactivity, gamification, and interconnectivity. As a new web-based media format with sophisticated game principles, SndBites offered great potential. While the SOUND series was still based on a linear storyline, in SndBites four main characters narrated the storyline from different perspectives. Youth could follow the storyline from the perspective of their character of choice by a simple mouse click, and switch at any time to the perspective of another main character. In this way they could (almost simultaneously) engage themselves in different perspectives of the narrative. SndBites also included game elements (e.g., discover the hidden codes in the storyline and win a prize).

\section{Mark My Words}

While we were working on the SndBites series, we started the Mark My Words research project. The aim of Mark My Words was to design a new research method to analyze interpersonal conversations on social media (Bouman, Drossaert, \& Pieterse, 2012). We used the Mark My Words methodology to create 'markers' in the storyline of SndBites. Markers are "distinctive and identifiable message elements." When these markers are powerful (in order to be remembered by the audiences), they can be a potential trigger for conversations (Singhal \& Rogers, 2002). We designed multiple markers and proactively incorporated these markers in the script of the SndBites series. Designing specific markers around health issues (safe sex, hearing loss prevention, moderate alcohol use) is a challenging process. The markers have to be unique to the series and attractive enough to serve as a potential conversation topic. They also have to be attuned to the target group, and last but not least, they need to fit organically into the storyline. Based on these four criteria, we created several SndBites markers: 'Double Dutch' (meaning 'protected sex by using both birth control pill and a condom'); 'Crispy Hot' (meaning 'sexually aroused'); 'Go Out, Plug In' (meaning 'enjoy clubbing and use ear plugs'); 'Nocktails' (meaning 'non-alcoholic cocktails'); and 'Happy Drinks' (meaning 'a drink without alcohol'). Apart from these specific health-related markers, the series name (SndBites) and the character names in the series (DJ Kozmoz, Eltjo, Sjarda, Mariset, and Tiejo) were used as markers. The fact that these markers needed to be integrated into the storyline puts pressure on the scriptwriting process. Additionally, the actors/actresses had to voice the markers fluently in their dialogues. For this reason, I informed the actors and the film crew about the Mark My Words research project and the 
importance of the markers. This facilitated the process; for example, in one scene, the actors enjoyed the marker crispy hot and succeeded in making it an organic part of the scene.

The goal of markers is two-fold: through uptake of practice, markers directly contribute to attaining an intervention's goals, but they also provide EE researchers with a tool to follow the uptake in online conversations which-because of the uniqueness of the word-are directly attributable to the intervention. In the digital age, these markers can easily be retrieved and/or isolated, to follow their diffusion and to analyze the course of the conversations around them. Markers can include digital stickers, animations, or augmented reality via Facebook Filters, Frames, or Snapchat Effects, appealing to the playfulness of the target audiences (Lutkenhaus, Jansz, \& Bouman, 2020).

\section{$U P 2 U$}

SndBites provided part of the motivation to develop our next interactive EE project in 2012 , called UP2U. This project aimed to address the issue of sexual boundaries and sexual harassment, specifically targeting youth aged 15-19 (Fig. 5.5).

The outline of the drama was based on input of the target group and pre-tested before production. Through focus group research we selected three situations in which sexual boundaries were most likely overstepped. The first situation was sexting, especially in private online conversations where young people feel relatively safe. The second situation was the combination of alcohol use and sex. And the last situation was 'gold digging': grooming someone with attention and gifts, in order to establish a sexual 'quid pro quo.' The question in all situations was: how far will you go? While watching the drama, youth could influence the story by making choices for the different characters. The 'backside' of every story contains a decision tree with different paths in which the story may continue. For example: does she show her breasts? Yes or no? The story continues in a different direction, depending on the viewers' choice. Through experiencing different results of their choices and the consequences of various behaviors, youth can develop skills to assert themselves. They can become empowered to show others where their boundaries lie and become more sensitized to identify the boundaries of others. UP2U is integrated in a national sexual education platform that is used by most schools in the Netherlands. The interactive drama lines are part of specific lessons on 


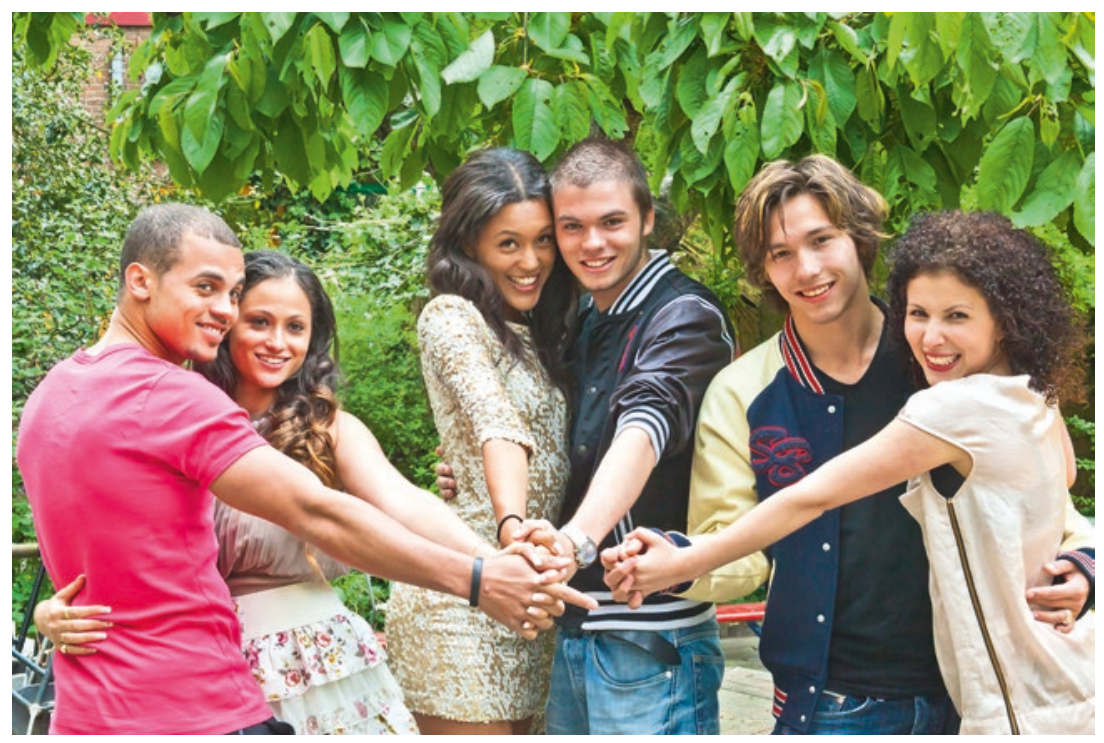

Fig. 5.5 The cast of UP2U. (Source CMH: Casper Cameraat)

sexual boundaries and are accompanied by assignments, group discussion, and teacher information.

Parallel to changes in the media landscape, storytelling formats and narrative approaches gradually shifted over the years from linear stories on television, such as in Villa Borghese, Medisch Centrum West, to web-based, non-linear, and interactive stories, as in SOUND, Sndbites, and UP2U. I experienced a steep learning curve, and there is always more to learn.

I remember how someone from the audience, during one of my presentations on EE and digital storytelling, asked me what I thought would be an ideal level of interactivity. He remarked, "Although the technical design in SndBites and UP2U allowed a certain level of interactivity, the stories were still designed by a single source from a more or less sender's perspective, weren't they?" I needed some time to answer and was pleasantly puzzled by his question. Then I realized that he was right. Although the storylines were based on extensive formative research and pre-tested among the intended audience, the interactivity was indeed more of a technological nature than of a social nature. Youngsters could switch the narrative perspectives in SndBites and could choose in UP2U how the stories 
evolved based on a decision tree, but they could not create new plots or add alternative stories. His question was an eye-opener, and made me want to explore even bolder ways of introducing EE narratives in the new media landscape.

\section{Main Kuch Bhi Kar Sakti Hoon Transmedia Series}

In 2019, we had a chance to experience and research how transmedia storytelling works in practice, in the Indian series Main Kuch Bhi Kar Sakti Hoon (MKBKSH) ('I, a woman, can achieve everything'). $\mathrm{CMH}^{6}$ was invited to become a collaborative research partner in the third season of $M K B K S H$. The series addresses sociocultural norms around family planning, gender equality, and sanitation. The social media team of Population Foundation India (PFI) set up story circles around these key issues, following a four-step cycle: Inspire, Enable, Activate, and Aggregate ${ }^{7}$ (Lutkenhaus et al., 2020). Seeking to promote gender equality early, the TV series depicted the practice of families celebrating the birthdays of their daughters (Inspire). Online, this practice was coined as celebrating Laadli Din - literally meaning 'girls day' - which is a marker for a practice that can easily be adopted (Enable). On the show's Facebook page, audiences were asked to share pictures of their loved ones (Activate), that were in turn combined into Facebook posts amplifying the support for this practice among the community (Aggregate). This led to a series of posts and comments with audiences showing how they have adopted Laadli Din in their lives, and to conversations about the role of girls and women in the family. The Laadli Din example shows that stories can not only challenge existing norms but also provide audiences with a new and uniquely labeled alternative that can easily be adopted (Lutkenhaus et al., 2020).

\section{New Partnership Arrangements}

What does the new media landscape with many more online, multiplatform developments and less linear formats mean for EE collaboration? In the early examples of Villa Borghese and Medisch Centrum West, the

${ }^{6} \mathrm{CMH}$ (Roel Lutkenhaus and Martine Bouman) was responsible for the social media research and joined Arvind Singhal and Helen Wang in the research team.

${ }^{7}$ https://www.facebook.com/mainkuchbhikarsaktihoon/ 
collaboration partners were television professionals and health professionals. In the late nineties when I studied these strategies for EE collaboration in television formats (Bouman, 1999, 2002; Reinermann, Lubjuhn, Bouman, \& Singhal, 2014), I concluded that if different professional domains want to collaborate, they have to have a feel for the game and know the habitus of each other's fields. Nowadays an EE collaboration requires a collaborative partnership that includes new media professionals, such as social influencers and their managing agencies, interaction designers, content strategists, programmers, and data analysts. All have unique professional and educational backgrounds (e.g., information technology, human-computer interaction, online marketing) (Lutkenhaus et al., 2020). To get a feel for the game in this environment, and to know the habitus of each other's fields, thus becomes even more challenging. This has severe consequences for health organizations. EE collaboration is a strange kind of marriage, of a somewhat promiscuous nature even, as it involves getting intimately acquainted with a lot of new and different partners over time. Health organizations have to realize that for successful EE, in every new project they have to engage themselves from scratch with new expertise; and create a new common frame of reference, accounting for different professional backgrounds, role sets, standards, professional norms, values, and ethics. As new technologies are evolving quickly, health organizations need to create a flexible and dynamic organizational structure to profit from the developments and chances for EE in the new media landscape. In this sense, an up-to-date health communicator also needs to be an up-to-date and involved media afficionado. That may prove a bigger challenge that meets the eye.

\section{Lessons Learned ANd Best Practices}

To effectively apply the entertainment-education strategy, knowledge and skills of both the academic and the applied setting are valuable and essential. The academic world has its own rhythm and working culture. In the media world, new technological developments arrive quickly. In order to keep from being overrun by the dynamic world of the creative media sector, it is important to design experiments that are closely linked to practice. This will allow us to take our results and lessons learned into the future.

Invest in partnerships. The health communication and media field demonstrate differences that in some respects make collaboration challenging. The design and implementation of EE programs demand close 
collaboration between different partners. The making of an EE program is the result of a negotiated agreement in which all partners have to give and take, and have to be willing to cross boundaries in order to create win-win options. It is important to start the collaboration by first creating a joint frame of reference and organizing a workshop or 'briefing retreat.'

Create a good balance between entertainment and education. The balance between entertainment and education is one of the most delicate and vulnerable aspects of the EE strategy. There are no cut and dried answers about the right balance. It is good to pre-test among intended audiences the framing and the educational value of the information given. It is generally agreed that too blatant a selling of the educational message kills the entertainment.

Adapt to new media to meet audiences where they are. New developments in media technology create opportunities for designing innovative entertainment media formats to meet audiences where they are. To tap the potential of the new media landscape for EE programs, an innovative and experimental mindset is key. However, the use of new technological devices, although interesting, also needs some reflections. Daan Roosegaarde (a Dutch designer) uses the term MAYA in his work, meaning Most Advanced Yet Acceptable. I like this expression. It is good to invent new things and experiment with out of the box EE concepts, but always within the reach of acceptability and adoptability. New media technologies can be of great help but only if they are accepted by and useful for the target audiences.

Acknowledgements I would like to thank the team at CMH (especially Hester Hollemans, Merlin Jurg, Sarah Lubjuhn, and Roel Lutkenhaus) for their collaboration on EE projects. Also thanks to AVRO/TROS broadcasting for collaboration and photos of Villa Borghese and $M C W$ and to Casper Cammeraat for photos of SOUND, SndBites, and UP2U.

\section{REFERENCES}

Bouman, M. (1999). The turtle and the peacock: Collaboration for prosocial change: The entertainment-education strategy on television. Netherlands: Landbouwuniversiteit Wageningen.

Bouman, M. (2002). Turtles and peacocks: Collaboration in entertainmenteducation television. Communication Theory, 12(2), 225-244. 
Bouman, M. P. A. (2016). Amusing Ourselves to Health and Happiness" Inaugural Lecture, Entertainment Media and Social Change aan het Erasmus Research Centre for Media, Communication and Culture (ERMeCC) van de Erasmus Universiteit Rotterdam (EUR).

Bouman, M., Drossaert, C. H. C., \& Pieterse, M. E. (2012). Mark my words: The design of an innovative methodology to detect and analyze interpersonal health conversations in web and social media. Journal of Technology in Human Services, $30(3-4), 312-326$.

Bouman, M., Hollemans, H. (2012). Sndbites. Formatief Onderzoek. Centrum Media \& Gezondheid.

Bouman, M. P. A., \& Jurg, M. E. (2006). Sound Effects, een pilotvoorlichtingscampagne ter preventie van gehoorschade bij jongeren. Grant proposal ZonMW project nr. 24500001.

Bouman, M. P. A., Maas, L., \& Kok, G. J. (1998). Health education in television entertainment: A Dutch drama serial. Health Education Research, $13(4), 503-518$.

Bouman, M. P. A., \& Wieberdink, E. A. M. (1993). Villa Borghese: A soapseries on heart health. Canadian Journal of Cardiology, 9, 145D-146D.

Bourdieu, P. (1993). The field of cultural production: Essays on art and literature. Cambridge: Polity Press.

Jenkins, H. (2006). Convergence culture: Where old and new media collide. New York: New York University Press.

Karpf, A. (1988). Doctoring the media. Routledge.

Louis, M. R. (1980). Surprise and sense making: What newcomers experience in entering unfamiliar organizational settings. Administrative Science Quarterly, $25,226-251$.

Lutkenhaus, R. O., Jansz, J., \& Bouman, M. P. A. (2019). Toward spreadable entertainment-education: Leveraging social influence in online networks. Health Promotion International. https://doi.org/10.1093/heapro/dazl 04

Lutkenhaus, R. O., Jansz, J., \& Bouman, M. P. A. (2020). Extending entertainmenteducation to the internet: Setting up story circles to stimulate conversations about social and behavioral change. [Doctoral dissertation]

Mackenbach, J. P. (1994). Ongezonde verschillen; over stratificatie en gezondheid in Nederland. Assen: Van Gorcum.

Nariman, N. (1993). Soap operas for social change: Toward a methodology for entertainment-education television. Westport: Praeger Publishers.

Petty, R. E., \& Cacioppo, J. T. (1986). The elaboration likelihood model of persuasion. Advances in Experimental Social Psychology, 19, 123-205.

Reinermann, J. L., Lubjuhn, S., Bouman, M., \& Singhal, A. (2014). Entertainmenteducation: storytelling for the greater, greener good. International Journal of Sustainable Development, 17(2), 176-191. 
ResCon. (1992). Dramaserie Villa Borghese; resultaten van een effectmeting. Den Haag: Nederladnse Hartstichting.

Rijs, K., Meeuse, J., Jurg, J., \& Bouman, M. (2007). Deelrapport 1: formatief onderzoek uitgaanspubliek: Meningen van jongeren over uitgaan en harde muziek: Rapport van 94 chat-interviews onder witgaande Nederlandse jongeren in de leeftijd van 16 tot 30 jaar. Boston: Center for Media \& Health.

Singhal, A., \& Rogers, E. M. (2002). A theoretical agenda for entertainmenteducation. Communication Theory, 12(2), 117-135.

Slater, M. D., \& Rouner, D. (2002). Entertainment-education and elaboration likelihood: Understanding the processing of narrative persuasion. Communication Theory, 12(2), 173-191.

Turow, J. (1989). Playing doctor: Television, storytelling, and medical power. Oxford: Oxford University Press.

Wang, H., \& Singhal, A. (2018). Audience-centered discourses in communication and social change: The "Voicebook" of Main Kuch Bhi Kar Sakti Hoon, an entertainment-education initiative in India. Journal of Multicultural Discourses, 13(2), 176-191.

Wang, H., \& Singhal, A. (2016). East Los High: Transmedia edutainment to promote the sexual and reproductive health of young Latina/o Americans. American Journal of Public Health, 106(6), 1002-1010.

Weick, K. E. (1995). Sensemaking in organizations. Thousand Oaks: Sage Publications. 
Open Access This chapter is licensed under the terms of the Creative Commons Attribution-NonCommercial-NoDerivatives 4.0 International License (http:// creativecommons.org/licenses/by-nc-nd/4.0/), which permits any noncommercial use, sharing, distribution and reproduction in any medium or format, as long as you give appropriate credit to the original author(s) and the source, provide a link to the Creative Commons licence and indicate if you modified the licensed material. You do not have permission under this licence to share adapted material derived from this chapter or parts of it.

The images or other third party material in this chapter are included in the chapter's Creative Commons licence, unless indicated otherwise in a credit line to the material. If material is not included in the chapter's Creative Commons licence and your intended use is not permitted by statutory regulation or exceeds the permitted use, you will need to obtain permission directly from the copyright holder. 